03

\title{
Фотоиндуцированное поглощение терагерцевого излучения в полуизолирующем кристалле GaAs
}

\author{
() А.С. Курдюбов ${ }^{1}$, А.В. Трифронов ${ }^{1}$, И.Я. Герловин ${ }^{1}$, И.В. Игнатьев ${ }^{1}$, А.В. Кавокин ${ }^{1,2}$ \\ ${ }^{1}$ Лаборатория оптики спина, Санкт-Петербургский государственный университет, \\ Санкт-Петербург, Россия \\ ${ }^{2}$ Школа фризики и астрономии, Университет Саутгемптона, \\ Хайфилд, Саутгемптон, Великобритания \\ E-mail: kurdyubov@yandex.ru
}

(Поступила в Редакцию 8 декабря 2016 г.)

\begin{abstract}
Экспериментально изучено влияние оптической подсветки на прохождение терагерцевого излучения через объемный кристалл полуизолирующего GaAs. Установлено, что без подсветки поглощение электромагнитных волн с частотой порядка $1 \mathrm{THz}$ в исследуемом кристалле практически отсутствует. Оптическая подсветка в области фундаментального поглощения кристалла не влияет на пропускание терагерцевых волн. В то же время при подсветке немного ниже края фундаментального поглощения, т.е. фактически в область прозрачности, пропускание терагерцевого излучения резко падает. При температуре жидкого гелия максимальный эффект достигается при энергии оптических фотонов примерно на $30 \mathrm{meV}$ меньшей ширины запрещенной зоны кристалла. Дальнейшая отстройка подсветки в область меньших энергий сопровождается практически полным восстановлением пропускания. С увеличением температуры образца спектральная область эффективного действия подсветки смещается вместе со сдвигом края фундаментального поглощения в сторону меньших энергий фотонов.
\end{abstract}

Работа поддержана грантом РФФИ 15-59-30406 РТ.

DOI: 10.21883/FTT.2017.07.44586.437

\section{1. Введение}

В последнее время начинает активно осваиваться участок спектра электромагнитных волн между СВЧи дальним ИК-диапазонами, соответствующий терагерцевой области частот. Тот факт, что в этом диапазоне лежат частоты колебательных переходов в большинстве молекул, открывает перспективу практических применений терагерцевого излучения в таких областях как медицина, характеризация материалов и изделий, сверхбыстрые системы связи, охранные системы и т.д [1-7]. В настоящее время не существует компактных и дешевых источников и приемников терагерцевого излучения [8], поэтому усилия большого числа исследователей направлены на разработку приборов такого типа. Среди большого числа систем, предлагаемых для создания терагерцевого излучателя, одними из наиболее перспективных являются полупроводниковые гетероструктуры, отличающиеся малыми размерами и хорошо отработанными способами их изготовления $[8,9]$. При этом свойства реальных полупроводниковых структур в терагерцевой области спектра и их зависимость от внешних воздействий изучены еще достаточно слабо.

В настоящей работе представлены результаты экспериментального исследования фотоиндуцированного поглощения терагерцевого излучения объемными полуизолирующими кристаллами $\mathrm{GaAs}$, которые используются как подложки для выращивания полупроводниковых гетероструктур эпитаксиальными методами. Поглощение индуцировалось лазерным светом, спектрально попадающим на край фундаментального поглощения GaAs.

\section{2. Описание эксперимента}

Исследования проводились на экспериментальной установке, реализующей метод терагерцевой спектроскопии с временным разрешением (time-domain terahertz spectroscopy, THz-TDS) (рис. 1) [4]. Ее отличительной особенностью является возможность измерения временного профиля электрического поля терагерцевого импульса. Преобразование Фурье временного профиля сигнала позволяет получить спектр терагерцевых импульсов.

Генерация терагерцевого излучения осуществлялась путем облучения нелинейного кристалла ZnTe фемтосекундными импульсами перестраиваемого Ті-сапфирового лазера, генерирующего импульсы с частотой $80 \mathrm{MHz}$ (см. рис. 1). Лазерный пучок с помощью светоделителя разделялся на две компоненты. Более мощная компонента (пучок накачки - pump) использовалась для возбуждения терагерцевых волн в нелинейном кристалле, а вторая компонента (reference) формировала опорный сигнал в схеме детектирования. В результате процесса оптического выпрямления в кристалле ZnTe фемтосекундный импульс накачки вызывает диэлектрический отклик среды, сопровождаемый испусканием импульса терагерцевого излучения, спектр которого определяется огибающей фемтосекундных импульсов. Для эффективного преобразования оптического излучения в терагерцевое нами использовался кристалл ZnTe c ориентацией (110) толщиной $1 \mathrm{~mm}$. C помощью пары внеосевых параболических зеркал терагерцевое излучение перефокусировалось на образец. 


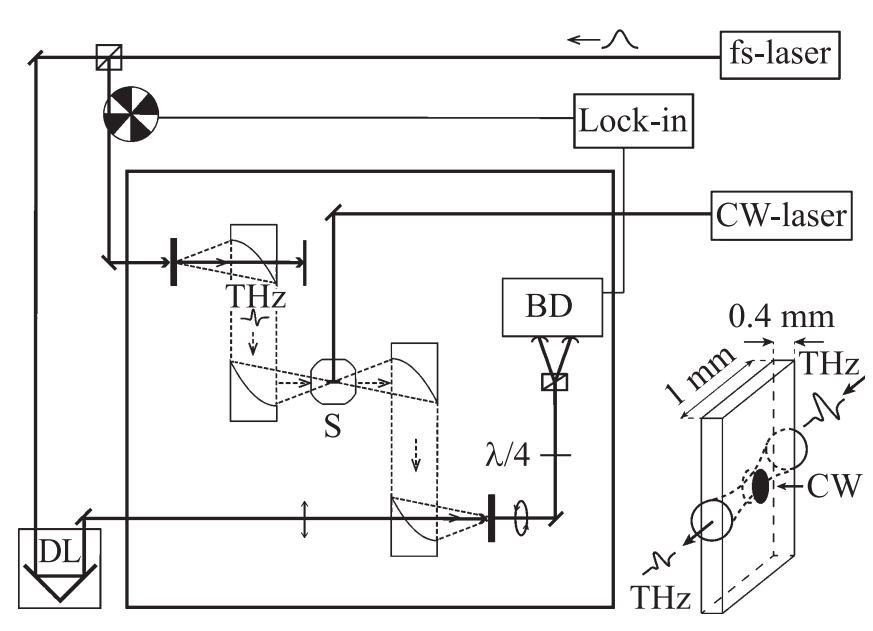

Рис. 1. Схема экспериментальной установки: fs-laser - фемтосекундный лазер, CW-laser - непрерывный лазер, DL линия задержки, $\lambda / 4-$ четвертьволновая фазовая пластинка, BD - балансный детектор, Lock-in - синхронный детектор, $\mathrm{S}$ - образец в криостате. На вставке показана геометрия эксперимента по фотоиндуцированному изменению пропускания терагерцевого излучения.

Образец представлял собой тонкую пластину высокочистого монокристаллического арсенида галлия, выращенного методом Чохральского с жидкостной герметизацией расплава [10], стандартно используемую в качестве подложки для эпитаксиального роста полупроводниковых гетероструктур. Образец помещался в гелиевый криостат замкнутого цикла, допускавший охлаждение до температуры $T=3.5 \mathrm{~K}$.

С помощью второй пары внеосевых параболических зеркал прошедшее через образец терагерцевое излучение перефокусировалось на второй нелинейный кристалл ZnTe с ориентацией (110) толщиной $0.5 \mathrm{~mm}$, входящий в систему детектирования сигнала. Электрооптический эффект Поккельса, индуцированный линейно поляризованным электрическим полем терагерцевой волны, приводит к возникновению в кристалле линейного двулучепреломления. В результате этого эффекта линейная поляризация зондирующего лазерного луча при прохождении через кристалл становится эллиптической (показано на рис. 1 двухсторонней стрелкой и овалом соответственно). Наведенное электрическим полем терагерцевой волны изменение эллиптичности поляризации опорного пучка (reference) регистрировалось с помощью стандартной поляризационной балансной схемы (см. рис. 1) [11,12].

Оптическая линия задержки в канале reference позволяет контролируемым образом изменять временной интервал между терагерцевым и опорным импульсами. Сканирование этого интервала делает возможной непосредственную регистрирацию терагерцевых осцилляций электрического поля на детектирующем кристалле. Пре- образование Фурье полученного сигнала дает при этом спектр терагерцевого импульса.

Задача экспериментов заключалась в изучении влияния дополнительной оптической подсветки на прохождение терагерцевого излучения через исследуемый образец. Подсветка создавалась излучением непрерывного титан-сапфирового лазера, который перестраивался в диапазоне энергий фотонов 1440-1540 meV. Мощность подсветки составляла около $30 \mathrm{~mW}$, диаметр пятна фокусировки - около $500 \mu \mathrm{m}$. Подсвечивающее излучение направлялось по нормали к плоскости образца, т. е. перпендикулярно направлению распространения терагерцевого излучения, фокусируемого в торец образца, как это схематически показано на вставке на рис. 1. Вследствие малой поперечной толщины образца $(0.4 \mathrm{~mm})$, сопоставимой с длиной волны терагерцевого излучения $(0.3 \mathrm{~mm})$, часть терагерцевого излучения неизбежно проходила мимо образца и попадала на детектор. Из-за большого коэффициента преломления кристалла GaAs для терагерцевых волн $(n=3.6$ [4]), терагерцевое излучение, прошедшее через образец, было задержано, приблизительно, на 8 ps и не перекрывалось во времени с излучением, прошедшим мимо образца. Помимо этого, проходящее мимо образца терагерцевое излучение в значительной степени экранировалось элементами крепления образца.

Для уменьшения поглощения терагерцевого излучения парами воды в атмосфере часть экспериментальной установки, за исключением лазеров, линии задержки и верхней части криостата, была помещена в герметичный бокс. Для осушения воздуха в боксе использовался силикагель, а также продувка бокса сухим азотом. Эти меры позволяли снизить влажность воздуха до 1\%.

\section{3. Результаты}

На рис. 2 представлены временные профили напряженности электрического поля терагерцевых импульсов, прошедших через образец. Профили измерены как в отсутствие подсветки, так и при подсветке лазерным излучением. На вставке приведены Фурье-спектры сигналов. Спектры имеют сложную структуру, обусловленную поглощением остаточных паров воды при прохождении терагерцевого излучения через атмосферу. Полная ширина спектров определяется длительностью импульсов накачки, а также нелинейными оптическими свойствами кристаллов ZnTe. Эксперименты показали, что подсветка с энергией фотонов на $20 \mathrm{meV}$ выше края фундаментального поглощения и мощностью, не превышающей $P=100 \mathrm{~W} / \mathrm{cm}^{2}$, не оказывает заметного влияния на пропускание терагерцевого излучения образцом. В то же время при энергии подсветки, на $20 \mathrm{meV}$ меньшей ширины запрещенной зоны GaAs (т.е. ниже края фундаментального поглощения), пропускание терагерцевого излучения образцом резко уменьшается. Изменение пропускания в наших экспериментах 


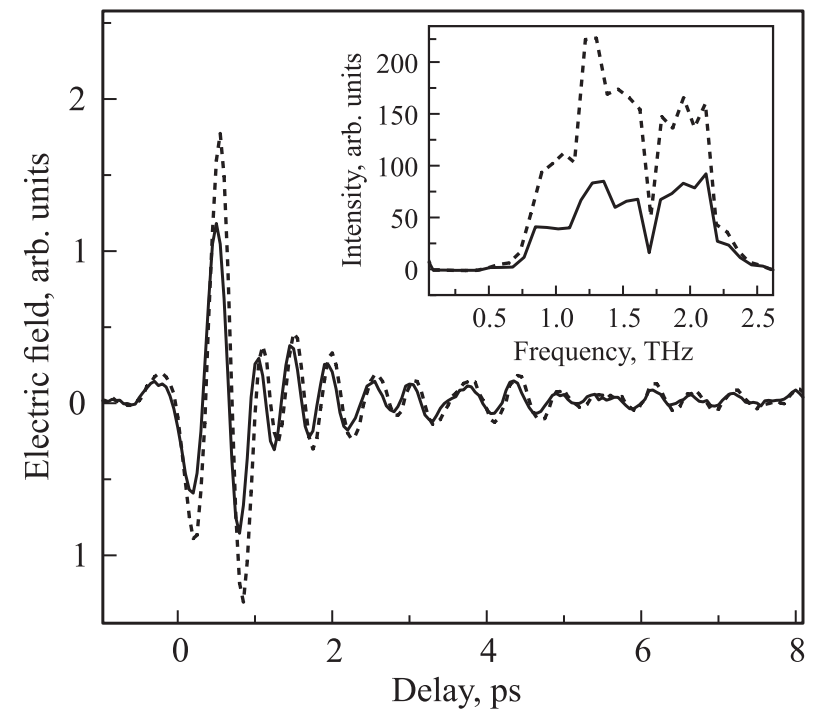

Рис. 2. Терагерцевый сигнал, измеренный без дополнительной подсветки (пунктирная кривая) и с подсветкой (сплошная кривая) мощностью $20 \mathrm{~mW}$ и энергией фотонов $1500 \mathrm{meV}$. Tемпература образца $3.5 \mathrm{~K}$. На вставке показаны Фурье-спектры сигналов.

определялось по уменьшению интегральной мощности терагерцевого излучения, прошедшего через образец в изучаемом диапазоне частот.

Для более детального исследования обнаруженного эффекта мы изучили зависимость величины терагерцевого поглощения от энергий фотонов оптической подсветки. Рис. 3, а демонстрирует спектр действия подсветки и его температурные изменения. При температурах, не превышающих $20 \mathrm{~K}$, спектральная область действия подсветки составляет примерно $20 \mathrm{meV}$ в окрестности $1500 \mathrm{meV}$. Повышение температуры сопровождается некоторым уменышением интегрального поглощения и сдвигом спектра действия в область меньших энергий фотонов. Вплоть до температуры $60 \mathrm{~K}$ форма спектра возбуждения наведенного поглощения почти не изменяется - спектр по-прежнему представляет собой сравнительно узкий контур. Однако при повышении температуры до $80 \mathrm{~K}$ спектр сильно трансформируется - вместо сравнительно узкого контура наблюдается плавное уменьшение пропускания в области меньших энергий, продолжающееся по крайней мере вплоть до $1440 \mathrm{meV}$, доступных в эксперименте.

Чтобы понять природу фотоиндуцированного поглощения терагерцевого излучения, мы измерили оптическое поглощение исследуемого образца в спектральной области ниже края фундаментального поглощения при различных температурах. Для этой цели излучение от источника сплошного спектра (лампы накаливания) направлялось по нормали к поверхности образца, т.е. в том же направлении, что и излучение непрерывного лазера (см. вставку на рис. 1). Прошедшее излучение регистрировалось спектрометром с охлаждаемой ПЗС- матрицей. По результатам измерений определялась оптическая плотность образца $D=-\lg \left(I_{\mathrm{tr}} / I_{0}\right)$, где $I_{0}-$ интенсивность падающего излучения, а $I_{\mathrm{tr}}-$ интенсивность прошедшего излучения.

Результаты измерений оптической плотности приведены на рис. 3, $b$. Как видно из рисунка, в области края фундаментального поглощения, приводящего к экспоненциально быстрому нарастанию оптической плотности образца, наблюдается дополнительная слабая полоса поглощения. Чтобы ее выделить, мы аппроксимировали край фундаментального поглощения экспоненциальной зависимостью в соответствии с правилом Урбаха $[13,14]$. Выделенный таким образом контур полосы имеет вид колоколообразной кривой (штриховая линия на рис. $3, b)$, центрированной приблизительно там же, где и полоса наведенного поглощения терагерцевого излучения (ср. с кривой на рис. 3, $a$ для $T=20 \mathrm{~K}$ ). С ростом температуры образца наблюдается сдвиг полосы дополнительного поглощения, который практически

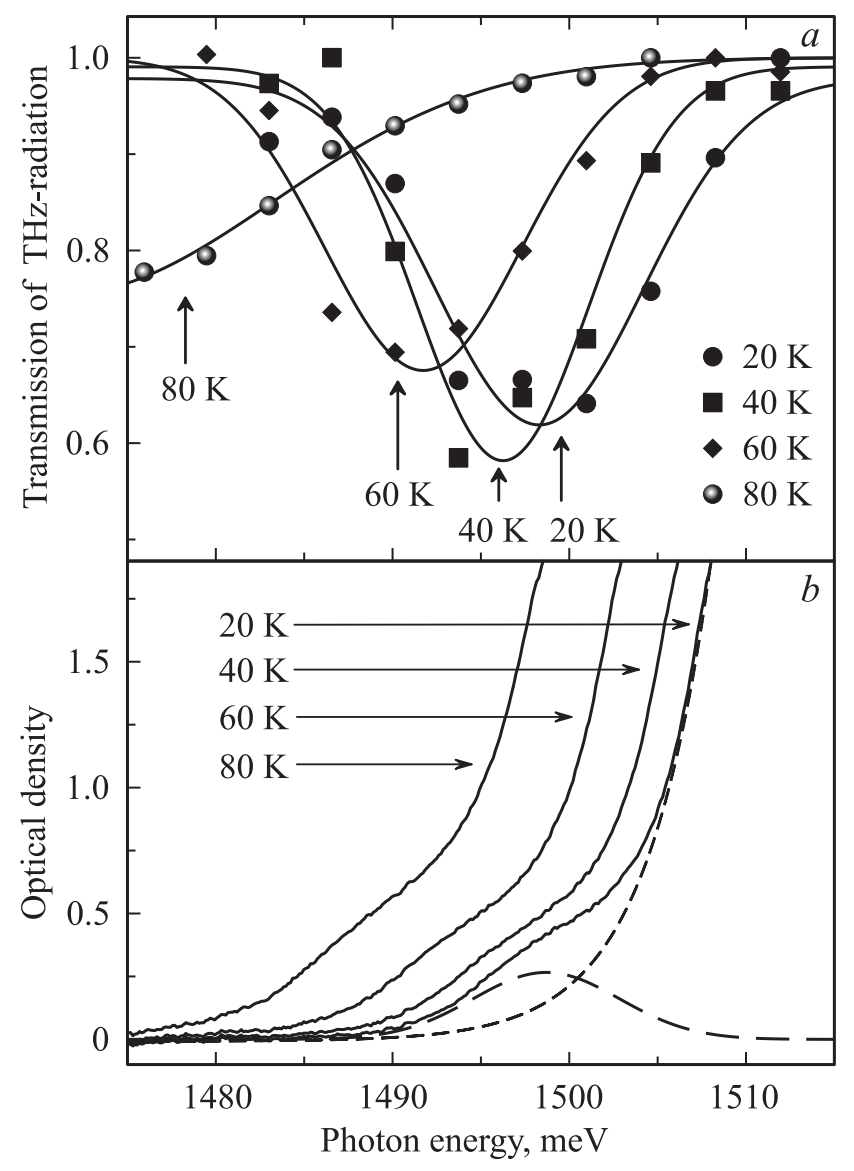

Рис. 3. $a-$ фотоиндуцированное изменение пропускания терагерцевого излучения при различных температурах и энергиях фотонов оптической подсветки. Символы - эксперимент, сплошные линии - аппроксимация функцией Гаусса. $b$ - температурные изменения спектра оптической плотности кристалла GaAs. Пунктирная линия - аппроксимация края фундаментального поглощения экспоненциальной кривой, штриховая линия - дополнительная полоса поглощения. 
воспроизводит температурный сдвиг края фундаментального поглощения. С другой стороны, он аналогичен сдвигу фотоиндуцированного поглощения терагерцевого излучения в диапазоне температур $T<80 \mathrm{~K}$. Однако при больших температурах наблюдается сильное расхождение спектров фотоиндуцированного терагерцевого поглощения и дополнительного поглощения, ср. кривые на рис. $3, a$ и $b$, измеренные при $T=80 \mathrm{~K}$.

\section{4. Обсуждение}

Основным механизмом поглощения терагерцевых волн с энергией фотонов, меньшей энергии оптических фононов в полупроводнике, считается взаимодействие со свободными носителями [15]. В исследованном нами полуизолирующем кристалле GaAs концентрация свободных носителей невелика, и поглощение терагерцевого излучения при распространении вдоль кристалла практически отсутствует. Более того, как показывают эксперименты, повышение температуры образца вплоть до комнатной температуры не приводит к заметному поглощению терагерцевого излучения. Это означает, что в исследуемом кристалле нет мелких донорных центров, которые могли бы быть ионизованы при таких температурах.

Оптическая подсветка в область фундаментального поглощения (1510 meV и выше) рождает большое количество свободных носителей. Однако из-за сильного поглощения излучения подсветки все носители образуются только в тонком приповерхностном слое и практически не влияют на прохождение терагерцевых волн через объем образца. Этим объясняется отсутствие заметного фотоиндуцированного поглощения в спектральном диапазоне выше $1510 \mathrm{meV}$ (см. рис. 3, $a$ ).

В то же время, как видно из рис. $3, b$, в области ниже края фундаментального поглощения наблюдается малоинтенсивная полоса, связанная, скорее всего, с возбуждением акцепторных примесных центров. Поглощение излучения подсветки такими центрами будет сопровождаться рождением свободных носителей, наличие которых должно привести к возникновению дополнительного поглощения на терагерцевых частотах. Поскольку коэффициент поглощения оптической подсветки в этом случае невелик, носители рождаются во всем объеме кристалла и тем самым эффективно ослабляют проходящее сквозь кристалл терагерцевое излучение. Резкое смещение спектра действия подсветки при повышении температуры до $80 \mathrm{~K}$ в область меньших энергий указывает на то, что в этих условиях основной вклад в формирование поглощения терагерцевых волн начинают давать более глубокие центры. В частности, это могут быть так называемые EL2-центры, которые могут значительно влиять на электрические и оптические свойства GaAs [16]. Для проверки гипотезы об оптической активации глубоких центров EL2 в наших условиях требуются дополнительные эксперименты.

\section{5. Заключение}

Эксперименты показали, что облучение полуизолирующего кристалла GaAs в спектральной области ниже края фундаментального поглощения сопровождается резким ослаблением пропускания кристалла на терагерцевых частотах. Этот эффект может быть объяснен наличием в исследуемом кристалле акцепторных центров, оптическое возбуждение которых приводит рождению носителей в зоне проводимости, поглощающих терагерцевое излучение. Измерение спектра действия оптической накачки и его температурных вариаций могут быть использованы для изучения центров поглощения в изучаемом объекте. С практической точки зрения обнаруженный эффект может быть использован для активного управления терагерцевыми пучками. Кроме того, эффект фотоиндуцированного поглощения терагерцевого излучения необходимо учитывать при оптических исследованиях терагерцевых свойств гетероструктур, выращенных на подложках GaAs.

Авторы благодарят В.Я. Алешкина и А.А. Дубинова за плодотворное обсуждение, ресурсный центр „Нанофотоника“ и МРЦ по направлению „Нанотехнологии“ СПбГУ за техническую поддержку работы.

\section{Список литературы}

[1] D. Dragoman, M. Dragoman. Prog. Quantum Electron. 28, 1, 1 (2004).

[2] В.Г. Беспалов. Опт. журн. 73, 11, 28 (2006).

[3] В.М. Исаев, И.Н. Кабанов, В.В. Комаров, В.П. Мещанов. Докл. ТУСУРа, 4, 34, 5-21 (2014).

[4] X.-C. Zhang, Jingzhou Xu. Introduction to $\mathrm{THz}$ Wave Photonics. Springer, N.Y. (2010). 246 p.

[5] O. Cherkasova, M. Nazarov, A. Shkurinov. Opt. Quantum Electron. 48, 217 (2016).

[6] H.-J. Song, T. Nagatsuma. IEEE transactions on terahertz science and technology. (2011). V. 1, N 1, 256-263.

[7] A.Y. Pawar, D.D. Sonawane, K.B. Erande, D.V. Derle. Drug Invention Today 5, 2, 157-163 (2013).

[8] G. Chattopadhyay. IEEE transactions on terahertz science and technology. (2011). V. 1, N 1. pp. 33-53.

[9] Y.-S. Lee. Principles of Terahertz Science and Technology. Springer, N.Y. (2009). 340 p.

[10] L. Hrivnák. Czech. J. Phys. B 34, 436 (1984) .

[11] Е.Б. Александров, В.С. Запасский. Оптика и спектроскопия 41 5, 855 (1976).

[12] Е.Б. Александров, В.С. Запасский. О фотонах и спинах. СПбГУ, СПб. (2009). 253 с.

[13] F. Urbach. Phys. Rev. 92, 1324 (1953).

[14] В.Л. Бонч-Бруевич, С.Г. Калашников. Физика полупроводников. Наука, М. (1990). 688 с.

[15] P.G. Huggard, J.A. Cluff, G.P. Moore, C.J. Shaw, S.R. Andrews, S.R. Keiding, D.A. Ritchie. J. Appl. Phys. 87 5, 2382 (2000).

[16] Y. Oyama, H. Dezaki, Y. Shimizu, K. Maeda. Appl. Phys. Lett. 106, 022109 (2015). 